\title{
Acervos bibliográficos do fim do século XIX: contribuições da Literatura Brasileira
}

\author{
Magali Lippert da Silva Almeida \\ Doutora; Instituto Federal de Educação, Ciência e Tecnologia do Rio Grande do Sul (IFRS), Porto \\ Alegre, RS, Brasil; \\ magali.lippert@poa.ifrs.edu.br
}

\begin{abstract}
Resumo: Este estudo visa demonstrar que é possível entender a formação do leitor brasileiro através da leitura e rastreamento das obras citadas nos romances e demais textos dos principais autores da Literatura Brasileira do fim do século XIX e início do século XX. O estudo aqui apresentado traz o levantamento dos textos citados pelo personagem/narrador Sérgio, do romance O Ateneu, de Raul Pompéia. Foi efetuada a leitura da obra e colhidas todas as menções literárias, a autores e textos, a partir disso foi elaborada uma lista das obras e do procedimento de citação do narrador/autor demonstrando que as obras e autores citados haviam sido lidos por ele no Brasil do fim do século XIX. É o início de um grande rastreamento que visa compor através da leitura dos livros de Raul Pompéia, Machado de Assis e outros importantes autores, os acervos brasileiros do fim do século XIX e início do século XX.
\end{abstract}

Palavras-chave: Acervos Brasileiros. Literatura Brasileira. Século XIX.

\section{Introdução}

Os estudos sobre os acervos que compunham as bibliotecas do fim do século XIX são raros e insuficientes para entendermos o processo de formação dos primeiros leitores brasileiros. O que se sabe é que até início do século XIX havia total precariedade no país na prestação de serviços de educação, cultura e informação. Entretanto, em 1808, com a vinda da família real portuguesa para o Brasil, houve a fundação de teatros e clubes, bem como o investimento na Biblioteca Real (cujo acervo havia sido trazido de Portugal).

Era um novo tempo para a leitura e os livros no Brasil: grupos de importantes escritores foram se destacando. Mesmo após o retorno da família real para 
Portugal, boa parte do acervo real ficou no Brasil (vindo a compor, inicialmente, o Real Gabinete Português de Leitura e a Fundação Biblioteca Nacional).

Figuram alguns poucos, mas bons, estudos sobre os acervos do século XIX, o curioso é que esse esforço de composição, de pesquisa e de busca de quais seriam os títulos, os autores e os assuntos lidos na época se dão através de pesquisas exaustivas apoiadas em catálogos antigos e pesquisas de pesquisadores que fizeram levantamentos no início do século XX. O mais óbvio, especialmente levando em consideração que pesquisadoras como Lajolo e Zilberamann (2010) são oriundas da pesquisa em Letras/Literatura, seria rastrear os acervos tendo em vista o que é citado por escritores do fim do século XIX, como Machado de Assis, Raul Pompéia, Aluísio Azevedo, entre outros. Mas esse não foi o procedimento seguido pela maior parte dos pesquisadores.

Convencida, através de diversas leituras e conversas com intelectuais da Literatura e da Biblioteconomia, de que a forma mais segura de saber o que os acervos das bibliotecas brasileiras continham no fim dos anos de 1800 e início de 1900, venho dedicando-me a rastrear essas obras através das publicações literárias dos principais autores do século XIX. Em minha tese de doutorado, $A$ Biblioteca de Sérgio: representação do irrepresentável, rastreei todas as obras mencionadas por Raul Pompéia em O Ateneu, explorando contos do autor e os romances Uma tragédia no Amazonas e As joias da Coroa, bem como o livro de poemas Canções sem metro. Faltaram, apenas, as crônicas do autor, que não foram examinadas na íntegra. Meus estudos das obras de Machado de Assis e Lima Barreto também estão adiantados.

É importante destacar que apenas uma elite letrada consumia bens informacionais na época, e no centro dessa elite intelectual estavam os escritores, portanto é relevante acreditar que seu fazer literário incluía menções, divagações e inspirações de textos lidos por eles e que, mesmo que compusessem apenas seus acervos pessoais estavam circulando de alguma forma no Brasil, pois é sabido que Raul Pompéia, por exemplo, jamais viajou ao exterior. Foi através dessa reflexão que encontrei uma lacuna nos estudos sobre os acervos do fim do século XIX, pois muitos textos que Pompéia cita em $O$ Ateneu, por exemplo, não figuram nas listas de pesquisadores como Tambara (2003), Lajolo e Zilber- 
man (2010), ou seja, havia livros circulando por aqui, sendo lidos (mesmo que pela elite intelectual) que são ignorados pelos estudiosos do livro e da leitura.

\section{Metodologia}

Quanto à metodologia empregada neste estudo, primeiramente foi realizada a leitura da obra $O$ Ateneu, foram sendo identificadas todas as menções a livros, textos e autores. Nem sempre as menções eram claras, muitas vezes partiam de observações vagas e divagações, sendo assim, foram necessárias muitas leituras e atenção constante para identificar possíveis “textos” por trás de devaneios do personagem (por exemplo).

Foi realizada a leitura de toda a obra literária do autor Raul Pompéia, facilitando assim a percepção de citações que, embora não referenciadas, pertenciam a outros autores (a citação sem referência era uma prática comum entre os autores de literatura do século XIX), ou seja, foi necessário conhecer bem o estilo literário de Raul Pompéia.

Após a leitura de toda a obra de Pompéia e a identificação mencionada acima, partiu-se para a revisão bibliográfica sobre a obra do autor, sua biografia e a crítica literária sobre $O$ Ateneu, bem como sobre a época que a obra foi escrita, contextualizando, assim, o estudo.

Feito isso, a autora deste artigo partiu para as leituras de todos os textos (principalmente livros) mencionados direta ou indiretamente pelo escritor. Comparou-se, então, o texto lido pela autora com a representação feita por Pompéia em $O$ Ateneu, comprovando (e isso foi possível) a leitura que Pompéia fez de tais obras, evidenciando, assim, que essas obras figuravam nos acervos brasileiros do fim do século XIX, pois Pompéia nunca saiu do país.

\section{Sérgio: o típico leitor do fim do século XIX}

Um excelente exemplo do percurso do leitor brasileiro do fim do século XIX é descrito por Raul Pompéia através de seu mais importante personagem: Sérgio. O Ateneu, publicado em 1888, obra máxima de Pompéia e um dos mais impor- 
tantes romances brasileiros de todos os tempos traz uma excelente representação de um estudante/leitor e o seu caminho pelo universo da leitura e da literatura.

Sérgio é o personagem/narrador da obra $O$ Ateneu, para muitos o alter ego de Raul Pompéia. O personagem é matriculado pelo pai em um colégio interno e, a partir daí, começa sua narrativa sobre as venturas e desventuras de sua estada no colégio. As leituras são a forma que Sérgio encontra de fugir da realidade exasperante que vive no internato.

Independente dos traços autobiográficos da obra, o que é relevante ressaltar é que o percurso do personagem Sérgio e o de seu criador Raul Pompéia é bastante semelhante, o que evidencia que as leituras efetuadas por Sérgio eram também (ou o foram em algum momento) de Raul Pompéia. O percurso escolar de ambos, como representantes dos filhos da elite, também é o mesmo.

Os tutores e os poucos colégios existentes custavam caro, eram tradicionalmente considerados privilégio dos ricos e, claro, tirariam jovens do campo, da loja ou de qualquer outro local onde estivessem contribuindo para a sobrevivência econômica de suas famílias. Em 1872, para adotarmos uma data intermediária, "em uma população estimada pelo censo em 10 milhões de habitantes, o total de matrículas nas escolas primárias não passava de 150 mil alunos."

Durante a Monarquia e a República Velha, os filhos de fazendeiros ricos, grandes comerciantes e homens de negócios, dos burocratas do alto escalão e dos profissionais abastados eram educados primeiro em casa, pelos pais ou tutores (em geral, europeus). Quando atingiam a idade adequada, seguiam para o colégio, que em geral encarnava a afirmação da liderança cultural da capital do estado ou da província. (NEEDELL, 1993, p. 74-75).

É exatamente como expõe Needell (1993) que Pompéia descreve a trajetória de aquisição do conhecimento por Sérgio:

Freqüentara como externo, durante alguns meses, uma escola familiar do Caminho Novo, onde algumas senhoras inglesas, sob a direção do pai, distribuíam educação à infância como melhor lhes parecia. [...] Lecionou-me depois um professor em domicílio. Apesar deste ensaio da vida escolar a que me sujeitou a família, antes da verdadeira provação, eu estava perfeitamente virgem para as sensações novas da nova fase. O internato! (POMPÉIA, 2005, p. 40-41).

Sérgio primeiro frequenta a escola familiar (onde senhoras inglesas lecionam), após este período um professor é contratado para lhe dar aulas em casa. 
Só depois dessas primeiras experiências escolares é que o menino ingressa no Internato. Nas duas primeiras experiências o contato de Sérgio não é institucional. Com Pompéia deu-se algo parecido, os primeiros ensinamentos em casa e depois a experiência no Internato de propriedade do Barão de Macaúbas, o Colégio Abílio e, só então, o ensino secundário no regime de externato, no Colégio Pedro II. Há no Ateneu certo escárnio de Pompéia ao construir personagens (principalmente professores e o próprio diretor) que demonstram a subjugação brasileira à cultura e ao ensino europeu.

Considerando a riqueza de detalhes que Raul Pompéia descreve na formação de Sérgio enquanto leitor, bem como o uso que este fazia da biblioteca do Internato em que cursou seus primeiros estudos, pretendo usar como exemplo tanto o personagem como o próprio autor, um dos mais importantes intelectuais do fim do século XIX. Para tal fiz a leitura da obra (mote de minha tese de doutorado) e da biografia do autor.

O personagem Sérgio relembra, em primeira pessoa (personagem/narrador), seus tempos de externato e aulas em casa de forma carinhosa, já a entrada e permanência no internato são traumáticas a ponto de serem relatadas, de forma escarnecida, na sua idade adulta. Quanto a Pompéia, são poucos os registros que relatam seus primeiros aprendizados. Nesse sentido, biógrafos afirmam que o escritor e suas irmãs foram alfabetizados pela mãe, dona Rosa Teixeira Pompéia, ainda em Angra dos Reis, onde o escritor viveu desde seu nascimento (em 1863) até 1873, ano em que a família fixa residência no Rio de Janeiro. Ainda em 1873 Raul Pompéia é matriculado no Colégio Abílio e, então, no Colégio Dom Pedro II, onde concluiu seu ensino secundário.

Pompéia formou-se, ainda, em Direito, percorrendo o caminho já destacado: ensino em casa, em internato o ensino primário, ensino secundário no mais importante colégio do Segundo Reinado, encerrando com o curso de Direito em Recife (que foi iniciado em São Paulo onde foi reprovado como represália as suas denúncias e ironias contra os professores e a faculdade). Quanto a Sérgio, só sabemos que ele chega ao internato e lá fica até o incêndio. Se fez um curso secundário, se estudou Direito ou Medicina, em São Paulo ou Recife, ninguém sabe, mas seu futuro era previsível, provavelmente seguiria os passos dos 
filhos da elite já que era oriundo de uma família abastada. O que é possível afirmar é que Raul Pompéia conhecia bem as instituições formais e por isso descreveu-as, de forma ficcional, mas altamente crítica, n'O Ateneu.

É possível perceber, nas entrelinhas do romance, que o acesso aos bens culturais no Ateneu (representando os colégios da época) eram limitadíssimos. Os alunos só tinham acesso à biblioteca através do Grêmio Literário, e era necessário passar por uma seleção para se associar ao clube. Fora isso, não havia possibilidade, a não ser através das aulas, de adquirir conhecimentos culturais.

Não é por acaso que há uma atmosfera de tédio em toda a obra. As possibilidades de distrações dos meninos eram praticamente nulas e, dentro dessa precariedade, eles tentavam se distrair, brincando, brigando ou se pervertendo. Sérgio, que teve a "sorte" de ter seu nome aprovado pela agremiação (Grêmio Literário Amor ao Saber), passava - boa parte de seu tempo - lendo para combater o tédio.

Espantar o tédio através da leitura parece ser um dos passatempos favoritos dos personagens criados pelos mais importantes escritores do fim do século XIX. Em Machado de Assis as personagens mulheres são leitoras vorazes e está claro, na descrição das personagens, a rotina tediosa apaziguada pela leitura. Nos romances românticos, especialmente nos livros de José de Alencar, também é possível notar a presença da leitura na rotina feminina.

Mas de onde saíam esses livros, como eram adquiridos e, pensando nos estudantes em idade escolar, a qual acervo tinham acesso?

\section{Os acervos bibliográficos e os leitores do fim do século XIX no Brasil}

As bibliotecas, como conhecemos hoje, eram raras no fim do século XIX, pequenos acervos formavam salas de leitura em escolas e casas de famílias abastadas. O livro era visto mais como objeto de decoração nas casas das ricas famílias e como demonstração (aparente) de conhecimento e poder do que como instrumento real de informação. Chartier (1996) ao analisar a presença de livros nos ambientes retratados no século XVIII, observa: "O papel do livro no retrato masculino encontra-se aí deslocado: de atributo estatutário, índice de uma con- 
dição ou função, torna-se companheiro de solidão. Na tradição, o livro é decoração e a biblioteca, sinal de um saber ou de um poder." (CHARTIER, 1996, p. 90).

A imprensa começou a atuar no Brasil após 1808 também em função do novo contexto político do país, este fato oportunizou a impressão de jornais e a atuação de intelectuais brasileiros na elaboração de textos jornalísticos e literários. A literatura de folhetim passa a ser divulgada nesta época, caindo rapidamente no gosto do público tendo em vista a curiosidade que tais textos, publicados em capítulos, despertavam.

[...] o romance folhetim foi uma febre nacional que impulsionou muitos dos nossos grandes autores a utilizarem esse espaço como forma de publicação de suas obras e projeção dos seus nomes entre o público e a crítica. Sendo o jornal o veículo de comunicação mais acessível na sociedade dos oitocentos, talvez este fosse o caminho mais rápido e fácil para o escritor alcançar notoriedade. (SALES, 2007, p. 45).

Os folhetins faziam sucesso entre o público letrado, no entanto, muitos autores além de publicar a obra seriada em jornais também publicavam na íntegra assim que o último capítulo era divulgado pelo jornal, foi assim que aconteceu com $O$ Ateneu.

Se os jornais ajudavam a aproximar leitores da literatura, por outro lado, a formação de bibliotecas (ou salas de leitura) estava longe de ser uma prioridade do governo imperial. A família real e a nobreza tinham acesso à biblioteca real, mas a plebe precisava utilizar outros meios para ter acesso ao conhecimento veiculado pelos livros.

Os comerciantes portugueses, atentos aos interesses de uma pequena, mas promissora, elite leitora passaram a comercializar livros ao mesmo tempo em que vendiam diversas outras coisas (ferramentas, embutidos, pães etc). Deste despreparo para acompanhar os novos paradigmas da época, problemas até então inexistentes surgem no contexto livreiro, como a questão do direito autoral, por exemplo, pois os impressores interessados neste mercado incipiente e cientes do interesse de leitores brasileiros por obras de escritores portugueses (como, 


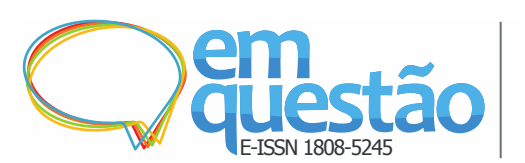

por exemplo, Eça de Queirós e Alexandre Herculano) publicavam essas obras sem nenhum pagamento aos autores portugueses.

A questão dos direitos autorais prolongou-se, ainda, por algumas décadas, recrudescendo no final da década de 1860 e início da década de 1870. Nesta época, tanto autoridades brasileiras quanto portuguesas estavam mais empenhadas em regulamentar os direitos dos autores. [...] Por esta época, Portugal já possuía convenção sobre a propriedade literária com a Espanha e a França e negociava com a Bélgica. (FERREIRA, 2000, p. 4).

A primeira iniciativa relevante de uma biblioteca "acessível" a todos foi a do gabinete real de leitura. Ferreira listou os principais assuntos que figuravam no catálogo da biblioteca em 1858 :

Quadro 1 - Gabinete Português de Leitura - Catálogo de 1858

\begin{tabular}{|l|l|}
\hline Assunto & Quantidade \\
\hline Administração (em francês) & 17 \\
\hline Administração (em português) & 73 \\
\hline Artes e manufaturas & 69 \\
\hline Biografias & 119 \\
\hline Culto & 114 \\
\hline Dicionários & 144 \\
\hline Direito Civil & 313 \\
\hline Direito Eclesiástico & 118 \\
\hline Economia política & 176 \\
\hline Educação & 105 \\
\hline Filosofia & 133 \\
\hline História & 924 \\
\hline História Eclesiástica & 130 \\
\hline Legislação & 130 \\
\hline Literatura & 500 \\
\hline Medicina & 211 \\
\hline Novelas e romances & 1614 \\
\hline
\end{tabular}




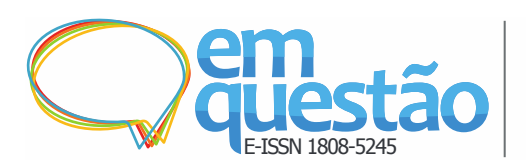

\begin{tabular}{|l|l|}
\hline Poesia & 404 \\
\hline Política & 276 \\
\hline Teatro & 210 \\
\hline Teologia & 210 \\
\hline Variedades & 204 \\
\hline Viagens & 196 \\
\hline Suplemento & - \\
\hline Administração & 23 \\
\hline História & 15 \\
\hline Novelas e romances & 19 \\
\hline Total & 6.347 \\
\hline
\end{tabular}

Fonte: Ferreira (2000, p. 7)

Podemos perceber, analisando o quadro acima, que em meados do século XIX o acervo total do gabinete real de leitura era do tamanho de muitos acervos de bibliotecas escolares atuais. Mesmo assim, o que mais se destaca é o número do acervo literário que é apresentado como de 1614 entre romances e novelas (aparece, no fim da lista, mais 19, o mesmo acontece com História que também se repete na lista), 404 de obras poéticas e 500 obras de literatura que devem abranger outros gêneros e 210 obras de teatro. Então temos, de um acervo de 6.347 livros, 2.728 obras literárias, por volta de $40 \%$ do acervo total.

Sobre a formação de leitores no fim do século XIX, Galvão e Batista (1998) observam que

A partir da segunda metade do século XIX, começaram a surgir no país, ainda que alguns fossem impressos na Europa, livros de leitura destinados especificamente às séries iniciais de escolarização. Em 1868, Abílio César Borges iniciou a publicação de uma das séries mais editadas no período. Os livros foram considerados inovadores no momento em que foram editados: o Primeiro Livro, destinado ao aprendizado inicial da leitura e da escrita, poderia substituir as cartilhas grosseiras ou os materiais manuscritos. Os demais livros da série tinham um caráter enciclopédico, trazendo conteúdos de várias áreas do conhecimento. De cunho mais instrutivo do que moral, os livros de Borges foram aplaudidos pela crítica intelectual da época, sendo reeditados várias vezes, educando gerações de brasileiros. (GALVÃO; BATISTA, 1998, não paginado). 
Em O Ateneu, Sérgio comenta sobre os livros elementares de Aristarco (o diretor do Internato Ateneu, que seria o mesmo Abílio Cesar Borges ou Barão de Macaúbas), Pompéia demonstra, na trajetória de seu personagem, o caminho da aquisição do conhecimento pelas crianças da época. Sobre isso Zilberman (1996) lembra que um dos primeiros livros didáticos a circular no Brasil foi o Tesouro dos Meninos, na mesma época também foi publicado Leitura para Meninos. O público eram crianças que estavam aprendendo a ler e assim também assimilavam padrões morais e estudavam o conteúdo de disciplinas curriculares como geografia, cronologia, história de Portugal e história natural. É possível perceber a sintonia entre a passagem citada abaixo, do artigo de Zilberman (1996), e as referências às leituras que Sérgio fazia em O Ateneu.

Os catálogos de livros vendidos no Brasil da época traziam títulos como: Alfabeto para instrução da mocidade; Arte poética de Horácio, por Cândido Lusitano; Coleção de cartas para meninos; Compêndio de retórica; Elementos de sintaxe; Gramática latina; Gramática portuguesa; Instrução da retórica; Instrução literária; Retórica de Gilbert e Retórica de Quintiliano. O catálogo de obras que se vendem na loja de Paulo Martim oferece Leituras juvenis e morais, voltado provavelmente à formação dos jovens (ZILBERMAN, 1996).

Zilberman (1996) também observa que "[. . .] o mercado parecia insatisfatoriamente provido, razão por que durante o século XIX, proliferaram queixas, denunciado o estado deficitário da educação da infância e a ausência de livros didáticos apropriados.” (ZILBERMAN, 1996, p. 16).

Os acervos escolares se restringiam a livros didáticos, a alguns livros literários (a maioria de literatura moral ou textos de aventura) e obras de referência como dicionários, enciclopédias e compêndios.

Lajolo e Zilberman (2010), no livro Literatura Infantil Brasileira: história e histórias, fizeram um levantamento de livros e autores lidos por crianças e adolescentes e que figuravam nos acervos escolares na segunda metade do século XIX. Seguem as obras citadas pelas autoras: Fábulas, de La Fontaine, editado entre 1668 e 1694, As aventuras de Telêmaco, de Fénelon, lançadas postumamente em 1717, e os Contos da Mamãe Gansa, cujo título original era Histórias ou narrativas do tempo passado com moralidades, que Charles Perraut publicou 
em 1697. Os contos de fadas de Perraut também foram um grande sucesso, assim como as adaptações dos clássicos: Robinson Crusoé (1769), de Daniel Defoe e Viagens de Gulliver (1726), de Jonathan Swift. São citados também pelas autoras Hans Christian Andersen com Contos (1833), Lewis Carroll, com Alice no país das maravilhas (1863), Collodi, com Pinóquio (1883), e James Barrie, com Peter Pan (1911). Também eram populares as histórias de aventura, cujos principais representantes foram: James Fenimore Cooper, em $O$ último dos moicanos (1826), Júlio Verne, nos vários livros publicados a partir de 1863 e Robert Louis Stevenson em A ilha do tesouro (1882). Ainda Cônego Von Schmid, em Os ovos de Páscoa (1816), a Condessa de Ségur, em As meninas exemplares (1857), Louise M. Allcott, em Mulherzinhas (1869), Johanna Spiry, em Heidi (1881), e Edmond de Amicis, em Coração (1886). As autoras citam, ainda as Leituras para meninos (já citada anteriormente) e As aventuras do Barão de Münchhausen (1848).

Dos livros disponíveis para leitura na segunda metade do século XIX, são os listados acima que foram mencionados por Lajolo e Zilberman (2010). Ao todo há menção a dezenove autores, das obras citadas, três são de leitura destinada a meninas e um deles (Peter Pan) foi publicado após O Ateneu Sendo assim contaremos com obras que poderiam ter sido lidas pelo personagem/narrador. Sérgio menciona em O Ateneu diversas leituras na sua infância, alguns figuram na lista das autoras, sete (quase metade) delas, o que demonstra que era uma criança que aproveitava a oferta literária da época, teve acesso à boa parte dos livros citados e isto se deu, principalmente, em função de seu ingresso no Ateneu e do acesso à biblioteca do colégio. Entretanto, é de suma importância notar aqui que muitas outras obras citadas pelo personagem Sérgio, e que o autor, Raul Pompéia, com certeza leu, pois discorre em O Ateneu sobre tais textos, não são citadas pelas pesquisadoras, o que demonstra a lacuna em seguir, apenas, catálogos e pesquisas antigas sobre os acervos do século XIX.

Levando em consideração a oferta da época é possível perceber que o personagem de Raul Pompéia vai tecendo suas leituras com o que tinha disponível na biblioteca da escola e que possibilitou que Sérgio, o persona- 
gem/narrador, lesse: Os Lusíadas, Nova Floresta, Robinson Crusoé, Paulo e Virgínia, entre outros.

Em suas descrições das leituras que fez na escola, Sérgio chama a atenção para os textos e personagens que o marcaram: "Possuía minha literatura completa de tesouros de meninos, contos de Schmidt; [...]" (POMPÉIA, 2005, p. 149). O narrador se refere a obras de literatura infanto-juvenis bastante comuns nas bibliotecas das escolas da época. Sobre os livrinhos que compunham uma espécie de obra enciclopédica conhecida como "Tesouro de meninos".

[...] o Tesouro de Meninas e o seu congênere, o Tesouro de Meninos. Publicados originalmente na Europa, estes livros ajudaram a difundir modelos de comportamento para os/as filhos/as das camadas médias e altas da sociedade brasileira do Império. O conteúdo dessas obras mesclava lições de história, geografia e ciências naturais com lições de ordem moral constituindo um compêndio de conhecimentos gerais para uso nas escolas e na educação doméstica. Os textos destes livros foram compostos no formato de diálogos em que um personagem adulto ensina às crianças as regras do bem viver dentro e fora de casa. Como recursos didáticos, estes livros se valiam de contos, fábulas e biografias de celebridades históricas, de modo a introjetarem nos/as pequenos/as leitores/as os exemplos de conduta que deveriam seguir. Através de suas páginas, meninos e meninas deveriam aprender, assim, a representar os papéis sociais almejados por seus progenitores numa sociedade organicamente constituída. (GONÇALVES FILHO, 2011, p. 200).

A obra enciclopédica, que segundo Sérgio ele possuía inteira, tem muito da literatura que ele já descrevera anteriormente, moralista como a do Conselheiro Bastos e cheias de regras de comportamento e bem viver, ao estilo das máximas. Segundo Tambara (2003): "Os textos de leitura de cunho 'ideológicomoral' eram representados, além dos já citados, principalmente pelas "Fábulas de Esopo", pelo "Thesouro de Meninos" de Pedro Blanchard, e pelo "A Ciência do Bom Homem Ricardo" de Benjamin Flanklin." (TAMBARA, 2003, p. 8).

O narrador também faz referência aos contos de Schmidt: sobre esta obra pouco se sabe, mas no interessante estudo de Tambara (2003), intitulado "Livros de leitura nas escolas de ensino primário no século XIX no Brasil", há menção aos Contos de Schmidt, extraída de um relatório resultante de um levantamento das obras mais encontradas nas bibliotecas das escolas do Brasil Imperial: 
No Rio de Janeiro, em 1881, há o contrato entre o governo provincial e o Dr. Joaquim Manuel de Macedo para edição de duas obras elaboradas para uso das escolas primárias - A História do Brazil e a Chorographia da Província do Rio de Janeiro. Entretanto, tal iniciativa não altera, substancialmente a concentração em poucos títulos, dentre os quais se destacavam os seguintes:

\begin{tabular}{|c|c|}
\hline Títulos & volumes \\
\hline Contos de Schmidt & 2.775 \\
Segundo livro de leitura do dr. Abílio & 2.455 \\
Terceiro dito de idem & 2.088 \\
Catechismo de doutrina Christã & 2.799 \\
História Sagrada & 1.428 \\
\hline
\end{tabular}

(TAMBARA, 2003, p. 8)

Podemos perceber, analisando o quadro da citação acima, que os livros do Dr. Abílio também estavam entre os mais comuns nas escolas da época. Quanto aos Contos de Schmidt, livro de contos infantis, Tambara ressalta no trabalho já citado que:

É impressionante a quantidade de "Contos de Schmid" utilizados na província do Rio de Janeiro. Esta obra, a rigor, não aparece nas relações de textos utilizados nas demais províncias.

\begin{tabular}{|l|l|}
\hline \multicolumn{1}{|c|}{ Ano } & \multicolumn{1}{c|}{ Volumes } \\
\hline 1871 & 1.670 \\
1881 & 2.775 \\
1882 & 1.945 \\
1884 & 2.650 \\
\hline
\end{tabular}

(TAMBARA, 2003, p. 8).

O autor dos contos era o cônego alemão Christoph Von Schmid (17681854) cuja obra foi traduzida em diversos idiomas: "Antes de 1880, traduções de Cônego Schmid, como O Canário (1856), A cestinha de flores (1858) e Os ovos de Páscoa (1860), já circulavam no Brasil.” (VIDAL, 2004, p. 36).

Sendo a obra de um padre, podemos supor que a moral cristã se faz presente nos contos.

Sérgio continua citando as obras que leu no período em que era interno do Ateneu: "[...] visitara uma por uma no meu burrinho as feiras da sabedoria de Simão de Nântua; [...]” (POMPÉIA, 2005, p. 149). 
A obra referida por Sérgio se chama Histórias de Simão de Nantua ou o Mercador de Feiras de autoria do francês Laurent Pierre de Jussieu (17921866). Segundo os editores da edição portuguesa de 1867 (a primeira edição francesa data de 1818):

Offerecemos aos nossos caros correspondentes e respeitaveis leitores, uma nova edição do Simão de Nantua.

A primeira, esgotada já ha muito tempo, não tinha supprida; entretanto, é esta uma obra excellente para a educação moral da mocidade escrita por um distincto litterato portuguez, e por isso merece ser conservada no nosso catalogo. (AILLAUD; GUILLARD, 1867, p. 4).

O comentário dos editores deixa claro o estilo da obra: moralista. Assim como O Tesouro de Meninos e Os Contos de Schmid, este é mais um texto onde a moral e os bons costumes são pregados aos jovens leitores.

O narrador d'O Ateneu "viaja" visitando feiras como fazia Simão de Nântua, um mercador sábio e bom. O narrador de História de Simão de Nântua também escreve em primeira pessoa, como se fosse o próprio autor contando suas experiências de viagens e visitas a feiras com Simão, sendo assim ele vai descrevendo os conselhos que Simão dava às pessoas das quais se aproximava nas feiras. A obra é repleta de máximas como: "O trabalho cura a miseria e a economia impede que ella volte" (JUSSIEU, 1867, p. 11). "Os impostos mais pesados são aqueles que cada um lança a si mesmo pela ociosidade ou pela dissipação" (JUSSIEU, 1867, p. 12). Os conselhos de Simão são sempre moralistas e reacionários: defende o governo, o trabalho, fala mal de jogos, do ócio etc.

Tendo em vista o exposto acima podemos afirmar, sem receio de precipitação, que os acervos escolares eram compostos, em boa parte, de obras moralistas e religiosas. A maior parte das leituras do personagem tem essa característica, entretanto, O Ateneu é permeado por citações obscuras, referências não citadas, divagações que evidenciam a aquisição de leitura do autor, Raul Pompéia, mas não exatamente de seu personagem. Ao destrinchar a obra encontrei uma rica lista de livros que com certeza foram lidos pelo autor, e, portanto, de obras que ele encontrara no Brasil, em bibliotecas públicas ou acervos particulares. 
Abaixo segue a lista, com o procedimento de citação do autor, demonstrando que, com certeza, ele lera as obras.

Quadro 2 - Lista de obras

\begin{tabular}{|c|c|c|c|}
\hline AUTOR & $\begin{array}{l}\text { TÍTULO (página em } \\
\text { que aparece em } \\
\text { O Ateneu }\end{array}$ & $\begin{array}{l}\text { NACIONALIDADE } \\
\text { DO AUTOR }\end{array}$ & $\begin{array}{l}\text { PROCEDIMENTO } \\
\text { DE CITAÇÃO }\end{array}$ \\
\hline Vários & $\begin{array}{l}\text { Bíblia (p. 43, 86, 95, } \\
96,105,110,120,131, \\
162,181,213,256)\end{array}$ & Latim & $\begin{array}{l}\text { A maioria das menções } \\
\text { serve para representar } \\
\text { percepções do narrador. }\end{array}$ \\
\hline Charles Perrot & Cendrillon (p. 45) & Francês & $\begin{array}{l}\text { Narrador referencia a } \\
\text { obra para representar os } \\
\text { meninos do Ateneu em } \\
\text { apresentação pública } \\
\text { numa das festas do co- } \\
\text { légio. }\end{array}$ \\
\hline Juvenal & Sátira X (p. 49) & Greco-latina & $\begin{array}{l}\text { Narrador referencia a } \\
\text { obra para representar as } \\
\text { aulas de Ginástica no } \\
\text { Ateneu. }\end{array}$ \\
\hline $\begin{array}{l}\text { Honoré de Bal- } \\
\text { zac }\end{array}$ & $\begin{array}{l}\text { A mulher de trinta anos } \\
\text { (p. 55) }\end{array}$ & Francês & $\begin{array}{l}\text { Narrador referencia a } \\
\text { obra para representar } \\
\text { Ema. }\end{array}$ \\
\hline $\begin{array}{l}\text { Allonso de Vil- } \\
\text { legas / Pedro } \\
\text { Ribadaneira }\end{array}$ & $\begin{array}{l}\text { Flos Sanctorum } \\
\text { (p. 73) }\end{array}$ & Espanhol/ Português & $\begin{array}{l}\text { Narrador referencia a } \\
\text { obra para representar } \\
\text { determinado compor- } \\
\text { tamento de Franco. }\end{array}$ \\
\hline $\begin{array}{l}\text { François de } \\
\text { Salignac de La } \\
\text { Mothe Fénelon }\end{array}$ & $\begin{array}{l}\text { As aventuras de Telê- } \\
\text { maco: filho de Ulisses } \\
\text { (p. 83) }\end{array}$ & Francês & $\begin{array}{l}\text { Narrador referencia a } \\
\text { obra para representar, } \\
\text { ironicamente, determi- } \\
\text { nado comportamento de } \\
\text { Sanches. }\end{array}$ \\
\hline Padre Anchieta & $\begin{array}{l}\text { História do Brasil (p. } \\
84-85)\end{array}$ & Português & $\begin{array}{l}\text { Leitura de Sérgio no } \\
\text { internato. }\end{array}$ \\
\hline $\begin{array}{l}\text { Tomás de } \\
\text { Kempis / José } \\
\text { Inácio Roquette }\end{array}$ & $\begin{array}{l}\text { Imitação de Cristo } \\
\text { (p. 85-86) }\end{array}$ & Francês & $\begin{array}{l}\text { Leitura de Sérgio no } \\
\text { internato. }\end{array}$ \\
\hline Luis de Camões & $\begin{array}{l}\text { Os Lusíadas (p. 91, } \\
149,232)\end{array}$ & Português & $\begin{array}{l}\text { Leitura de Sérgio no } \\
\text { internato. }\end{array}$ \\
\hline
\end{tabular}




\begin{tabular}{|c|c|c|c|}
\hline Abreu & $\begin{array}{l}\text { Compêndio de Abreu } \\
\text { (p. 95) }\end{array}$ & Português & $\begin{array}{l}\text { Leitura de Sérgio no } \\
\text { internato. }\end{array}$ \\
\hline $\begin{array}{l}\text { José Joaquim } \\
\text { Rodrigues Bas- } \\
\text { tos (Conselhei- } \\
\text { ro Bastos) }\end{array}$ & $\begin{array}{l}\text { Os dois artistas ou Al- } \\
\text { bano e Virgínia (p. 102) }\end{array}$ & Português & $\begin{array}{l}\text { Narrador referencia a } \\
\text { obra para representar o } \\
\text { colega Ribas. }\end{array}$ \\
\hline $\begin{array}{l}\text { Theóphile Gau- } \\
\text { tier }\end{array}$ & $\begin{array}{l}\text { Sem referência a título } \\
\text { (p. 108) }\end{array}$ & Francês & $\begin{array}{l}\text { O narrador referencia a } \\
\text { poesia do autor para } \\
\text { representar o manto que } \\
\text { vestia Aristarco. }\end{array}$ \\
\hline $\begin{array}{l}\text { Manuel Bernar- } \\
\text { des (Padre) }\end{array}$ & Nova Floresta (p. 124) & Português & $\begin{array}{l}\text { Leitura de Sérgio no } \\
\text { internato. }\end{array}$ \\
\hline $\begin{array}{l}\text { Alexandre Her- } \\
\text { culano }\end{array}$ & $\begin{array}{l}\text { A Harpa do Crente (p. } \\
145)\end{array}$ & Português & $\begin{array}{l}\text { O narrador referencia a } \\
\text { obra para representar os } \\
\text { textos que Barreto es- } \\
\text { crevia para um periódi- } \\
\text { co do internato. }\end{array}$ \\
\hline José de Alencar & O Guarani (p. 145) & Brasileiro & $\begin{array}{l}\text { O narrador referencia a } \\
\text { obra para representar } \\
\text { um romance de rodapé } \\
\text { assinado por um tal } \\
\text { Aimbiré no periódico } \\
\text { do colégio. }\end{array}$ \\
\hline Plutarco & $\begin{array}{l}\text { Sem referência a título } \\
\text { (p. 193) }\end{array}$ & Greco-latino & $\begin{array}{l}\text { O autor seria tema de } \\
\text { um debate no Grêmio } \\
\text { Literário Amor ao Sa- } \\
\text { ber. }\end{array}$ \\
\hline Cícero & $\begin{array}{l}\text { Sem referência a título } \\
\text { (p. 145-147) }\end{array}$ & Greco-latino & $\begin{array}{l}\text { O narrador referencia o } \\
\text { autor com o interesse de } \\
\text { representar, ironica- } \\
\text { mente, Nearco. }\end{array}$ \\
\hline Júlio Verne & $\begin{array}{l}\text { A volta ao mundo em } \\
\text { oitenta dias (p. 148) }\end{array}$ & Francês & $\begin{array}{l}\text { Leitura de Sérgio no } \\
\text { internato. }\end{array}$ \\
\hline Júlio Verne & $\begin{array}{l}\text { Vinte mil léguas sub- } \\
\text { marinas (p. } 148,149)\end{array}$ & Francês & $\begin{array}{l}\text { Leitura de Sérgio no } \\
\text { internato. }\end{array}$ \\
\hline Júlio Verne & $\begin{array}{l}\text { As viagens e aventuras } \\
\text { do Capitão Hatteras (p. } \\
\text { 149) }\end{array}$ & Francês & $\begin{array}{l}\text { Leitura de Sérgio no } \\
\text { internato. }\end{array}$ \\
\hline Júlio Verne & $\begin{array}{l}\text { Os filhos do Capitão } \\
\text { Grant. v. } 3 \text { (p. 148) }\end{array}$ & Francês & $\begin{array}{l}\text { Leitura de Sérgio no } \\
\text { internato. }\end{array}$ \\
\hline Júlio Verne & $\begin{array}{l}\text { Viagem ao centro da } \\
\text { terra (p. 149) }\end{array}$ & Francês & $\begin{array}{l}\text { Leitura de Sérgio no } \\
\text { internato. }\end{array}$ \\
\hline Júlio Verne & $\begin{array}{l}\text { Cinco semanas em ba- } \\
\text { lão (p. 148, 149) }\end{array}$ & Francês & $\begin{array}{l}\text { Leitura de Sérgio no } \\
\text { internato. }\end{array}$ \\
\hline $\begin{array}{l}\text { Christoph Von } \\
\text { Schmid }\end{array}$ & $\begin{array}{l}\text { Contos de Schmid } \\
\text { (p. 149) }\end{array}$ & Alemão & $\begin{array}{l}\text { Leitura de Sérgio no } \\
\text { internato. }\end{array}$ \\
\hline Pedro & Tesouro de meninos (p. & Francês & Leitura de Sérgio no \\
\hline
\end{tabular}




\begin{tabular}{|c|c|c|c|}
\hline chard & 149) & & internato. \\
\hline $\begin{array}{l}\text { Laurent Pierre } \\
\text { de Jussieu }\end{array}$ & $\begin{array}{l}\text { Simão de Nântua ou O } \\
\text { Mercador de Feiras (p. } \\
\text { 149) }\end{array}$ & Francês & $\begin{array}{l}\text { Leitura de Sérgio no } \\
\text { internato. }\end{array}$ \\
\hline Jonathan Swift & $\begin{array}{l}\text { As viagens de Gulliver } \\
\text { (p. 149) }\end{array}$ & Irlandês & $\begin{array}{l}\text { Leitura de Sérgio no } \\
\text { internato. }\end{array}$ \\
\hline Blaise Pascal & $\begin{array}{l}\text { Sem referência a título } \\
\text { (p. 149) }\end{array}$ & Francês & $\begin{array}{l}\text { O narrador referencia o } \\
\text { autor ao representar o } \\
\text { personagem Gulliver de } \\
\text { Swift como uma espé- } \\
\text { cie de "Pascal de ma- } \\
\text { madeira". }\end{array}$ \\
\hline $\begin{array}{l}\text { Rudolf Erich } \\
\text { Raspe }\end{array}$ & $\begin{array}{l}\text { As aventuras do Barão } \\
\text { de Munchausen (p. } \\
\text { 149) }\end{array}$ & Alemão & $\begin{array}{l}\text { Leitura de Sérgio no } \\
\text { internato. }\end{array}$ \\
\hline $\begin{array}{l}\text { Giulio Cesare } \\
\text { Croce }\end{array}$ & $\begin{array}{l}\text { As aventuras de Bertol- } \\
\text { do (p. 149) }\end{array}$ & Italiano & $\begin{array}{l}\text { Leitura de Sérgio no } \\
\text { internato. }\end{array}$ \\
\hline Shakespeare & O Rei Lear (p. 149) & Inglês & $\begin{array}{l}\text { O narrador referencia a } \\
\text { obra para representar a } \\
\text { "odiosidade das suces- } \\
\text { sões" assim como no } \\
\text { "Testamento do Galo" }\end{array}$ \\
\hline Shakespeare & Hamlet (p. 154) & Inglês & $\begin{array}{l}\text { O narrador referencia } \\
\text { tragédia utilizando a } \\
\text { imagem de um crânio, } \\
\text { provavelmente em uma } \\
\text { alusão a Hamlet. }\end{array}$ \\
\hline $\begin{array}{l}\text { Gregório de } \\
\text { Matos }\end{array}$ & $\begin{array}{l}\text { Sem referência a título } \\
\text { (p. 153) }\end{array}$ & Brasileiro & 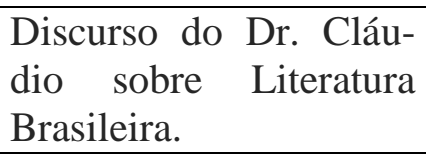 \\
\hline Antônio José & $\begin{array}{l}\text { Sem referência a título } \\
\text { (p. 153) }\end{array}$ & Brasileiro & 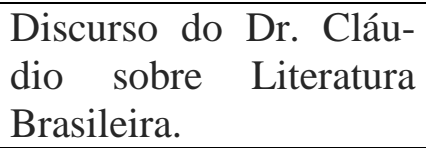 \\
\hline $\begin{array}{l}\text { Santa Rita Du- } \\
\text { rão }\end{array}$ & $\begin{array}{l}\text { Sem referência a título } \\
\text { (p. 153) }\end{array}$ & Brasileiro & $\begin{array}{l}\text { Discurso do Dr. Cláu- } \\
\text { dio sobre Literatura } \\
\text { Brasileira. }\end{array}$ \\
\hline Sousa Caldas & $\begin{array}{l}\text { Sem referência a título } \\
\text { (p. 153) }\end{array}$ & Brasileiro & 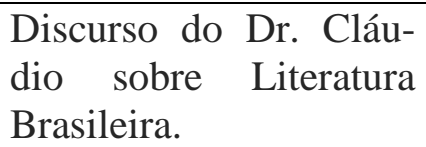 \\
\hline $\begin{array}{l}\text { Francisco de } \\
\text { São Carlos } \\
\text { (Frei) }\end{array}$ & $\begin{array}{l}\text { Sem referência a título } \\
\text { (p. 153) }\end{array}$ & Brasileiro & $\begin{array}{l}\text { Discurso do Dr. Cláu- } \\
\text { dio sobre Literatura } \\
\text { Brasileira. }\end{array}$ \\
\hline $\begin{array}{l}\text { Gonçalves de } \\
\text { Magalhães }\end{array}$ & $\begin{array}{l}\text { Sem referência a título } \\
\text { (p. 153) }\end{array}$ & Brasileiro & 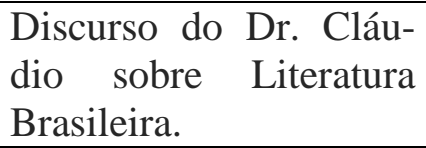 \\
\hline Gonçalves Dias & $\begin{array}{l}\text { Sem referência a título } \\
\text { (p. 153) }\end{array}$ & Brasileiro & $\begin{array}{l}\text { Discurso do Dr. Cláu- } \\
\text { dio sobre Literatura }\end{array}$ \\
\hline
\end{tabular}




\begin{tabular}{|c|c|c|c|}
\hline & & & Brasileira. \\
\hline Victor Hugo & $\begin{array}{l}\text { Os Miseráveis } \\
\text { (p. 155) }\end{array}$ & Francês & $\begin{array}{l}\text { O narrador referencia a } \\
\text { obra do autor que teria } \\
\text { tornado épica a expres- } \\
\text { são merde! represen- } \\
\text { tando o que um Senador } \\
\text { disse ao advogado Zé } \\
\text { Lobo. }\end{array}$ \\
\hline Emile Zola & A Taberna (p. 155) & Francês & $\begin{array}{l}\text { O narrador referencia a } \\
\text { obra do autor que teria } \\
\text { tornado clássica a ex- } \\
\text { pressão merde! repre- } \\
\text { sentando o que um Se- } \\
\text { nador disse ao advoga- } \\
\text { do Zé Lobo. }\end{array}$ \\
\hline Miguel Ângelo & $\begin{array}{l}\text { Sem referência a título } \\
\text { (p. 165) }\end{array}$ & Italiano & $\begin{array}{l}\text { Discurso do Dr. Cláu- } \\
\text { dio em que ele demons- } \\
\text { tra (e o narrador tam- } \\
\text { bém) seu repúdio a } \\
\text { forma em detrimento ao } \\
\text { conteúdo. }\end{array}$ \\
\hline Goethe & Fausto (p. 183) & Alemão & $\begin{array}{l}\text { O narrador referencia o } \\
\text { diabo Mefistófeles para } \\
\text { representar os olhos de } \\
\text { Melica. }\end{array}$ \\
\hline Homero & $\begin{array}{l}\text { Sem referência a título } \\
\text { (p. 174) }\end{array}$ & Greco-latino & $\begin{array}{l}\text { O narrador cita Homero } \\
\text { para representar as } \\
\text { imagens dos deuses em } \\
\text { selos que eram "nego- } \\
\text { ciados" no internato. }\end{array}$ \\
\hline Epicuro & $\begin{array}{l}\text { Sem referência a título } \\
\text { (p. 183) }\end{array}$ & Greco-latino & $\begin{array}{l}\text { O narrador referencia o } \\
\text { autor para representar o } \\
\text { comportamento interes- } \\
\text { seiro de Rômulo. }\end{array}$ \\
\hline $\begin{array}{l}\text { François Rabe- } \\
\text { lais }\end{array}$ & Pantagruel (p. 200) & Francês & $\begin{array}{l}\text { O narrador referencia o } \\
\text { autor para representar a } \\
\text { quantidade de comida } \\
\text { "rabelaisiana" levada ao } \\
\text { passeio no Jardim Bo- } \\
\text { tânico. }\end{array}$ \\
\hline Dante Alighieri & $\begin{array}{l}\text { A Divina Comédia } \\
\text { (p. 212, 246) }\end{array}$ & Italiano & $\begin{array}{l}\text { O narrador referencia } \\
\text { os personagens Fran- } \\
\text { cesca e Paolo para re- } \\
\text { presentar Cândido e } \\
\text { Tourinho. A obra tam- } \\
\text { bém é citada em função } \\
\text { de um discurso do Dr. }\end{array}$ \\
\hline
\end{tabular}




\begin{tabular}{|c|c|c|c|}
\hline & & & Cláudio. \\
\hline $\begin{array}{l}\text { Giacomo Leo- } \\
\text { pardi }\end{array}$ & $\begin{array}{l}\text { Sem referência a título } \\
\text { (p. 246) }\end{array}$ & Italiano & $\begin{array}{l}\text { Discurso do Dr. Cláu- } \\
\text { dio. }\end{array}$ \\
\hline Daniel Defoe & $\begin{array}{l}\text { Robinson Crusoé (p. } \\
220)\end{array}$ & Inglês & $\begin{array}{l}\text { Leitura de Sérgio no } \\
\text { internato. }\end{array}$ \\
\hline $\begin{array}{l}\text { Bernardin de } \\
\text { Saint-Pierre }\end{array}$ & $\begin{array}{l}\text { Paulo e Virgínia } \\
\text { (p. 220) }\end{array}$ & Francês & $\begin{array}{l}\text { Leitura de Sérgio no } \\
\text { internato. }\end{array}$ \\
\hline Jacques Delille & $\begin{array}{l}\text { Sem referência a título } \\
\text { (p. 223) }\end{array}$ & Francês & $\begin{array}{l}\text { O nome do professor de } \\
\text { Francês é igual ao do } \\
\text { poeta. }\end{array}$ \\
\hline Chateaubriand & $\begin{array}{l}\text { Sem referência a título } \\
\text { (p. 224-225) }\end{array}$ & Francês & $\begin{array}{l}\text { Leitura de Sérgio no } \\
\text { internato. }\end{array}$ \\
\hline Pierre Corneille & $\begin{array}{l}\text { Cina ou a Clemência de } \\
\text { Augusto (p. 224-225) - } \\
\text { Poliúto (p. 224-225) - } \\
\text { Horácio (p. 224-225) - } \\
\text { Cid (p. 224-225) }\end{array}$ & Francês & $\begin{array}{l}\text { Leitura de Sérgio no } \\
\text { internato. }\end{array}$ \\
\hline Jean Racine & $\begin{array}{l}\text { Atalia (p. 224-225) - } \\
\text { Britânico (p. 224-225) }\end{array}$ & Francês & $\begin{array}{l}\text { Leitura de Sérgio no } \\
\text { internato. }\end{array}$ \\
\hline Molière & $\begin{array}{l}\text { Misantropo (p. 224- } \\
\text { 225) - Tartufo (p. 224- } \\
\text { 225) }\end{array}$ & Francês & $\begin{array}{l}\text { Leitura de Sérgio no } \\
\text { internato. }\end{array}$ \\
\hline $\begin{array}{l}\text { Alexandre Du- } \\
\text { mas (pai) }\end{array}$ & $\begin{array}{l}\text { Sem referência a título } \\
\text { (p. 236) }\end{array}$ & Francês & $\begin{array}{l}\text { Leitura de Sérgio no } \\
\text { internato. }\end{array}$ \\
\hline Platão & $\begin{array}{l}\text { A República (p. 248- } \\
\text { 249) }\end{array}$ & Greco-latino & $\begin{array}{l}\text { Discurso do Dr. Cláu- } \\
\text { dio. Representação da } \\
\text { seleção dos melhores } \\
\text { pela escola. }\end{array}$ \\
\hline Schopenhauer & $\begin{array}{l}\text { Sem referência a título } \\
\text { (p. 273) }\end{array}$ & Alemão & $\begin{array}{l}\text { O narrador referencia o } \\
\text { autor quando se refere à } \\
\text { música que Ema toca } \\
\text { no piano. }\end{array}$ \\
\hline
\end{tabular}

Fonte: elaboração própria

Ao todo Sérgio faz quatorze menções à bíblia, dez do antigo testamento e quatro do novo testamento. Algumas menções são de leituras do menino, mas a maioria é utilizada para representar percepções do narrador.

Os contos de fadas são mencionados duas vezes pelo Sérgio adulto, são utilizados para representar os meninos do Ateneu (Cendrillon malfeito da burguesia) e os contos de maravilha (em contraposição a sombra do livro de notas). A menção a essas obras também ajuda Sérgio a representar o irrepresentável. 
Seis escritores Greco-latinos são citados por Sérgio (adulto), Homero, Juvenal (a teoria do mens sana in corpore sano), Cícero (como artifício utilizado pelo narrador para ridicularizar Nearco), Platão (A República), Plutarco e Epicuro. Pompéia era um excelente leitor de latim (a bíblia que utilizava e na qual havia várias anotações suas estava escrita em latim, também suas anotações pessoais estavam em latim). Todos os autores citados, coforme o quadro, foram utilizados para representar algo: ideologia (Juvenal "mente sã em um corpo são), comportamento (Nearco/Cícero e Rômulo "filosofava por Epicuro") imagem (o rosto, em um selo, de um dos deuses citados na obra de Homero), Platão e seu $A$ República foi utilizado para representar, no discurso do Dr. Cláudio, o colégio (e a seleção dos melhores). E o "sábio" Plutarco seria um dos temas de um debate no Grêmio Literário Amor ao Saber.

Quatro escritores italianos são citados pelo narrador: Dante, cujos personagens de A Divina Comédia (Francesca e Paolo) são utilizados para representar Cândido e Tourinho. A propósito, a obra de Dante também servirá para Sérgio descrever um discurso do Dr. Cláudio (o tronco que sangra em Dante). O narrador também cita a obra infantil Aventuras de Bertoldo, lida por ele no internato e cuja autoria é de Giulio Cesare Croce. O pintor e poeta Miguel Ângelo também figura entre os citados em um dos discursos do Dr. Cláudio transcritos por Sérgio, assim como Giacomo Leopardi, cujo nome não é citado diretamente, mas há a menção em um dos discursos do professor acerca da "giesta", o que, acreditamos, seja uma referência ao poema La Ginestra de Leopardi.

Dezenove franceses são citados por Sérgio; desses, dez autores foram lidos no internato por Sérgio quando criança (sendo que, de Júlio Verne e dos escritores de dramaturgia, foram vários livros). Todos os outros citados pelo narrador serviram para representar algo sobre o contexto que era descrito, seguem alguns exemplos: Ema (Balzaquiana), Sanches (a Minerva de Fénelon), a roupa de Aristarco (brisas trançadas de Gautier), a ofensa do senador contra Zé Lobo (merde! em Zola e Victor Hugo) e o professor de Francês do Ateneu, professor Delille (mesmo nome do poeta Jacques Delille).

Três escritores de língua inglesa figuram em O Ateneu: Shakespare, Defoe e Swift. Swift foi lido por Sérgio quando criança (um dos livros de aventura, 
mas com representações metafóricas críticas à sociedade inglesa o que ecoará na memória de Sérgio adulto). A obra Robinson Crusoé, de Daniel Defoe, também foi lida na infância e $O$ Rei Lear de Shakespeare utilizado para descrever o horror das sucessões e relacionado, no texto, com O Testamento do Galo (conjunto de quadras que antecedem o jogo do galo de tradição portuguesa).

Quatro autores de literatura alemã são citados pelo narrador, As aventuras do Barão de Munchausen e Contos de Schmid ambas lidas por Sérgio no internato. Os "olhos mefistofélicos de Melica" que provavelmente é uma relação com a obra Fausto (de Goethe) e Schopenhauer é utilizado para representar a música tocada por Ema.

Interessante que, dos sete autores portugueses citados, a maioria escrevia textos sobre religiosidade e moral, quatro deles. Entre os demais figuram Luis de Camões e o Padre Anchieta (cuja obra referenciada trata da História do Brasil), além de um "Abreu" que teria escrito um suposto Compêndio de Abreu (obra sobre a qual não encontramos maiores informações).

Oito escritores brasileiros são citados, todos pelo narrador (Sérgio quando criança não leu obras de autores brasileiros). A maioria dos autores brasileiros citados, sete, foi mencionada em um discurso do Dr. Cláudio (relembrado e narrado por Sérgio na vida adulta) sobre, justamente, literatura brasileira. O único citado diretamente pelo narrador (não através do personagem Dr. Cláudio) é José de Alencar e seu $O$ Guarani, ele menciona autor e obra para representar um texto "similar" publicado no periódico do colégio. Todos os brasileiros citados são autores do romantismo.

Por fim, ainda é importante constar que embora haja, em O Ateneu, uma atmosfera de crítica a poesia parnasiana, Pompéia não cita nenhum poeta parnasiano (seus contemporâneos), o autor, através de seu personagem/narrador menciona o parnasianismo através do personagem "Ítalo do Nascimento" um poeta parnasiano fictício, utilizado para representar, de forma irônica, todos os parnasianos.

\section{Considerações Finais}


O personagem Sérgio é representativo enquanto leitor do fim do século XIX. O autor, Raul Pompéia, demonstra através de seu personagem, o consumo de obras e de bibliotecas pelos estudantes das famílias ricas da época.

As representações das leituras de Sérgio criança demonstram o viés moralista e tendencioso dos textos aos quais o menino tinha acesso na primeira infância, essas representações tornam-se outras quando o personagem/narrador passa a frequentar a biblioteca: textos de aventura, comédias e dramas proporcionaram outras formas de percepção da realidade forçando o amadurecimento intelectual do leitor. Este caminho o levará às leituras e livros da vida adulta em que refere: Balzac, Gautier, Victor Hugo e Zola, entre outros.

Não se pode ignorar a influência dos livros na vida de Pompéia, seja como leitor, seja como autor e, até, gestor. Pompéia se tornou o mais poderoso bibliotecário do país em 1894, por um ano comandou a maior e mais completa biblioteca brasileira, a Biblioteca Nacional. Consta, nos arquivos da Fundação Biblioteca Nacional que Raul Pompéia conhecia, inclusive, o procedimento arquivístico da biblioteca.

As referências a leituras em $O$ Ateneu têm duas funções, para Sérgio criança é o simples descrever de suas aventuras, de sua fuga da realidade do internato, para o Sérgio adulto as referências têm a função de caracterizar outros personagens, representar situações, de dizer o indizível.

Muito mais do que um simples levantamento bibliográfico das leituras dos grandes escritores do fim do século XIX e início do século XX, o rastreamento das obras citadas por esses autores remonta os acervos literários da época e nos ajuda a compreender a formação de leitores no Brasil desde os tempos da Colônia, passando pela velha república até nossos dias. Ignorar que os acervos escolares da época contavam, predominantemente, com livros sobre a moral cristã, por exemplo, é um erro, pois as leituras moldam os sujeitos, que a representam e reproduzem culturalmente.

Reflexos das leituras efetuadas (ou citadas) no passado por escritores de relevância literária indiscutível como Machado de Assis, Lima Barreto, Aluísio Azevedo, Raul Pompéia e Euclides da Cunha, podem explicar o comportamento dos leitores, não leitores e pseudoleitores de nossos dias. 


\section{Referências}

AILLAUD, João Pedro. Advertencia dos editores. In: JUSSIEU, Laurent de. História de Simão de Nantua ou O Mercador de Feiras. Paris: Livraria de Vva J. P. Aillaud, Guillard E Ca., 1867.

CHARTIER, Roger. Do livro à leitura. In: CHARTIER, Roger (Org.). Práticas da leitura. São Paulo: Estação Liberdade, 1996.

FERREIRA, Tânia Maria Tavares Bessone da Cruz. Livros e sociedade: a formação dos leitores no século XIX. Revista Teias, Rio de Janeiro, v. 1, n. 1, 2000.

<http://www.periodicos.proped.pro.br/index.php/revistateias/issue/view/6>.

Acesso em: 29 jul. 2013.

GALVÃO, Ana Maria de Oliveira; BATISTA, Antônio Augusto G. A leitura na escola primária brasileira: alguns elementos históricos. Presença Pedagógica, Belo Horizonte, v. 4, n. 24. Disponível em: <http://www.unicamp.br/iel/memoria/Ensaios/>. Acesso em: 29 jul. de 2013.

GONÇALVES FILHO, Carlos Antônio Pereira. Livrinhos que eram verdadeiros tesouros: leituras para crianças no Brasil Imperial. Revista HISTEDBR Online, Campinas, n. 42, p. 200-216, jun., 2011. Disponível em: $\langle$ http://www.histedbr.fae.unicamp.br/revista/edicoes/42/art13_42.pdf>. Acesso em: 15 de janeiro de 2013.

LAJOLO, Marisa; ZILBERMAN, Regina. Literatura Infantil Brasileira: história e histórias. 4.ed. São Paulo: Ática, 1988.

JUSSIEU, Laurent de. História de Simão de Nantua ou O Mercador de Feiras. Paris: Livraria de Vva J. P. Aillaud, Guillard E Ca., 1867.

NEEDEL, Jeffrey.D. Belle Époque Tropical. São Paulo: Companhia das Letras, 1993.

POMPÉIA, Raul. O Ateneu. 2.ed. Cotia, SP: Ateliê Editorial, 2005.

SALES, Germana Maria Araújo. Folhetins: uma prática de leitura no século XIX. Entrelaces, Fortaleza, p.44-56, Ago., 2007. Disponível em: <http://www.entrelaces.ufc.br/germana.pdf>. Acesso em: 08 out. 2013.

TAMBARA, Elomar Antônio. Livros de leitura nas escolas de ensino primário no século XIX no Brasil. Anped, v. 26, 2003. Disponível em: <http://www.anped.org.br/reunioes/26/inicio.htm> . Acesso em: 24 jan. 2013. 


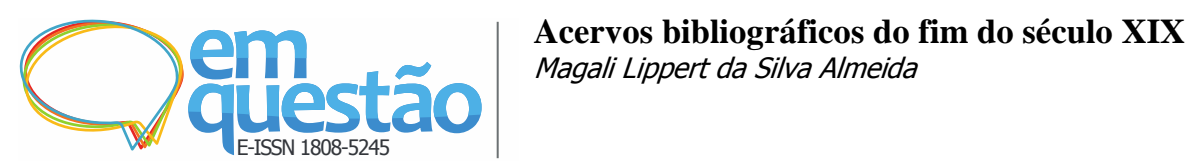

ZILBERMAN, Regina. No começo, a leitura. Em Aberto, ano 16, n. 69, Brasília/DF, jan./mar. 1996.

\title{
Library Collections of the late nineteenth century: contributions of Brazilian Literature
}

\begin{abstract}
There are few studies on the formation of the Brazilian readers in order to use the collections available in the country in the late nineteenth century. One of the apparent reasons is the difficulty of scholars track which works were present in Brazilian libraries of the time. This study aims to demonstrate that it is possible to fill this gap by reading and tracking of the works mentioned in the novels and other texts of the main authors of Brazilian literature of the late nineteenth century and early twentieth century. The study presented here provides a survey of the texts cited by the character/ narrator Sergio, the novel The Athenaeum, Raul Pompéia. The reading of the work was performed, collected all literary references, as well as authors and texts and then was made a list of the works and the quotation procedure of the narrator/author demonstrating that works and authors cited were read by him in Brazil the end of the nineteenth century. It is the beginning of a large tracking aimed at composing by reading the Raul Pompéia books, Machado de Assis, Aluísio Azevedo, Lima Barreto and Euclides da Cunha Brazilian literary collections of the late nineteenth century and early twentieth century.
\end{abstract}

Keywords: Brazilian Collections. Brazilian Literature. Nineteenth Century 
Recebido em 14/09/2015

Aceito em 17/12/2015 